\title{
Increased survival time of a patient with metastatic malignant melanoma following immunotherapy: A case report and literature review
}

\author{
YONG ZHANG, YONGPING SONG and QUANLI GAO \\ Department of Immunotherapy, The Affiliated Cancer Hospital of Zhengzhou University, \\ Zhengzhou, Henan 450003, P.R. China
}

Received August 1, 2014; Accepted April 13, 2015

DOI: $10.3892 / 01.2015 .3296$

\begin{abstract}
Metastatic malignant melanoma is treated with chemotherapy and radiotherapy. A number of previous studies have indicated that cytokine-induced killer cells (CIK cells) are a heterogeneous cell population that express cluster of differentiation (CD) 3 and CD56, in addition to the natural killer cell NKG2D activating receptor. CIK cells possess major histocompatibility complex-unrestricted cytotoxicity towards cancer, but not towards normal targets. The present study investigated whether the addition of CIK cells resulted in an improved therapeutic response in a patient with metastatic malignant melanoma. In the current case, a patient with metastatic malignant melanoma received CIK therapy, which resulted in a relatively long survival time of 28 months. To the best of our knowledge, there have been no previous studies reporting such positive effects in a patient who received CIK cell immunotherapy. Based on the findings of the present study, CIK cell therapy may be an option that results in a good prognosis in certain patients with metastatic malignant melanoma.
\end{abstract}

\section{Introduction}

Research indicates that the annual incidence of melanoma continues to increase $(1,2)$. Metastatic melanoma has a poor prognosis with a median survival time of 6-8 months and a 5 -year survival rate of $\sim 6 \%$ with chemotherapy $(3,4)$.

At present, immunotherapy is the fourth most common treatment approach for solid tumors, following surgery, chemo-

Correspondence to: Professor Quanli Gao, Department of Immunotherapy, The Affiliated Cancer Hospital of Zhengzhou University, 127 Dong Ming Road, Zhengzhou, Henan 450003, P.R. China

E-mail: gaoquanli1@aliyun.com

Key words: cytokine-induced killer cells, malignant melanoma, immunotherapy therapy and radiotherapy $(5,6)$. Numerous immunotherapy approaches using various killer cells for solid tumors have been reported in the literature, including tumor-infiltrating lymphocytes (TILs), lymphokine-activated killer cells (LAKs) and anti-CD3 monoclonal antibody-induced killer cells (7-9). The anti-tumor functions of TILs are major histocompatibility complex (MHC)-restricted and a number of patients with solid tumors are not eligible for TIL-based therapy since their TILs do not expand sufficiently, their tumors have lost expression of antigens or MHC molecules or they possess extremely low numbers of TILs (7). In addition, LAK and anti-cluster of differentiation (CD)3 monoclonal antibody-induced killer cells exhibit low anti-tumor activities (10). Therefore, due to their limited therapeutic efficacy, they are rarely used in the clinic. In 1991, Schmidt-Wolf et al (11) observed a novel type of antitumor effector cell, which was termed a cytokine-induced killer (CIK) cell. CIK cells proliferate rapidly in vitro, and possess strong antitumor activity against a broad spectrum of solid tumors (12). A number of clinical trials have reported that treating patients with metastatic solid tumors using CIK cells, alone or in combination with chemotherapy, significantly improves the median survival time, and in addition, that CIK cell transfusions may improve the immune function of patients (12-14). There is limited data on the use of CIK cell therapy for metastatic malignant melanoma (15). In the present study, a patient with metastatic malignant melanoma received CIK cell immunotherapy, which resulted in a relatively long overall survival time (OS) of 28 months

\section{Case report}

On November 1st, 2010, A 47-year-old female was admitted to The Affiliated Cancer Hospital of Zhengzhou University (Zhengzhou, Henan, China) with multiple skin metastatic melanoma nodes in the left leg (Fig. 1). Considering that metastatic malignant melanoma is resistant to chemotherapy and radiotherapy, CIK cell immunotherapy was administered. Mononuclear cells were collected from $50 \mathrm{ml}$ of the patient's peripheral blood and cultured in GT-T551 medium (Takara, Tokyo, Japan) containing anti-CD3 antibody (mouse-anti human monoclonal $\mathrm{IgG}_{2 \mathrm{a}}$; catalog no. sc-19590; Santa Cruz Biotechnology, Inc., Dallas, TX, USA; dilution, 1:300), 


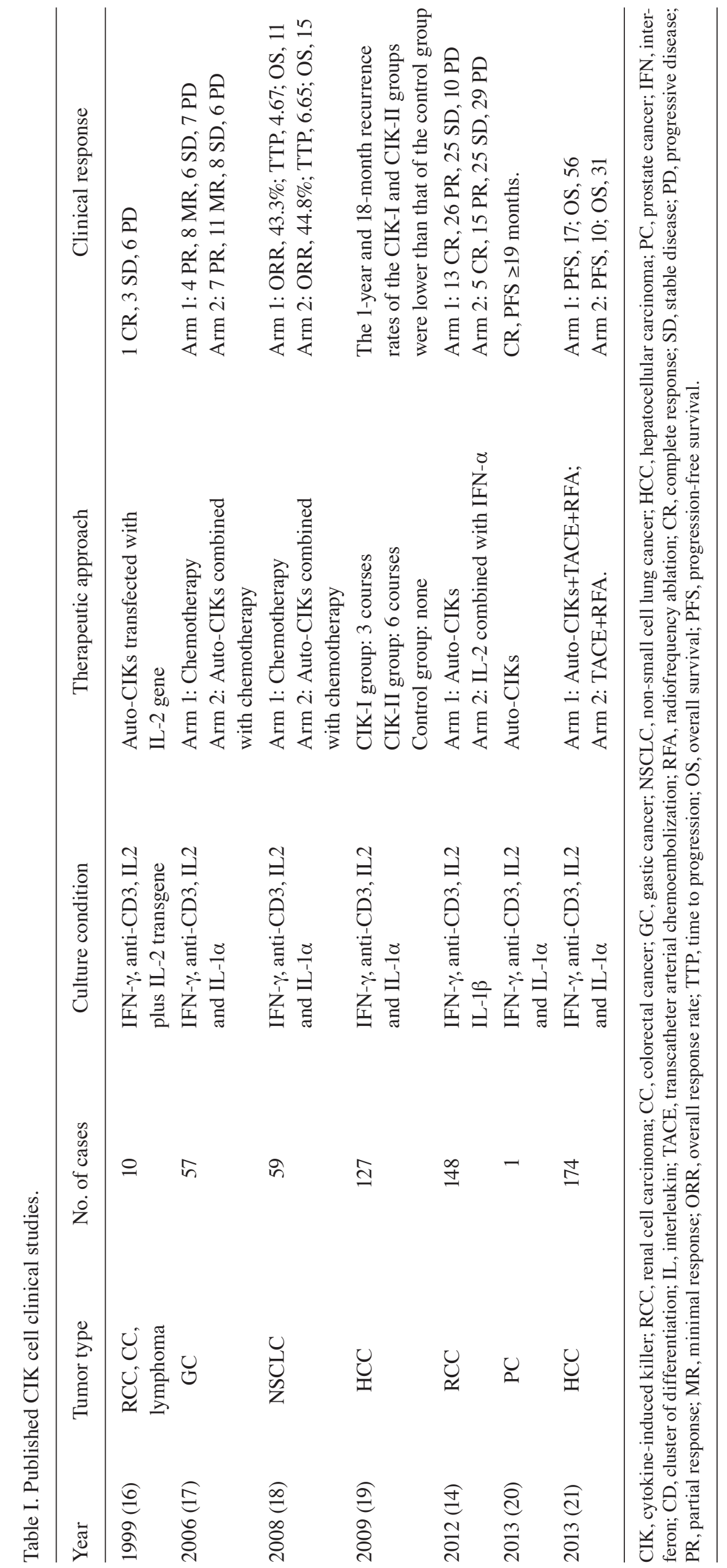




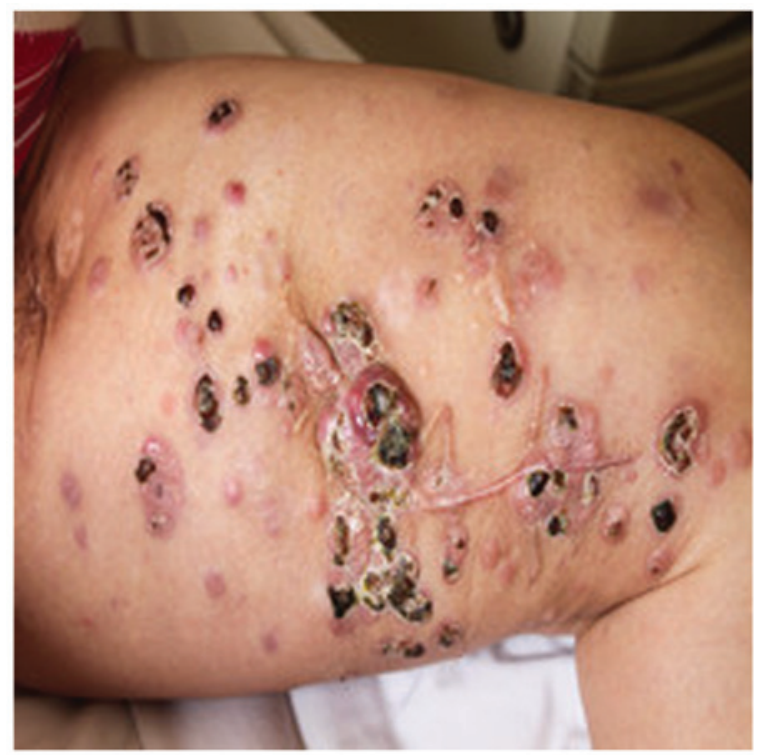

Figure 1. Metastatic melanoma nodes in the patient's left leg prior to cytokine-induced killer cell therapy.

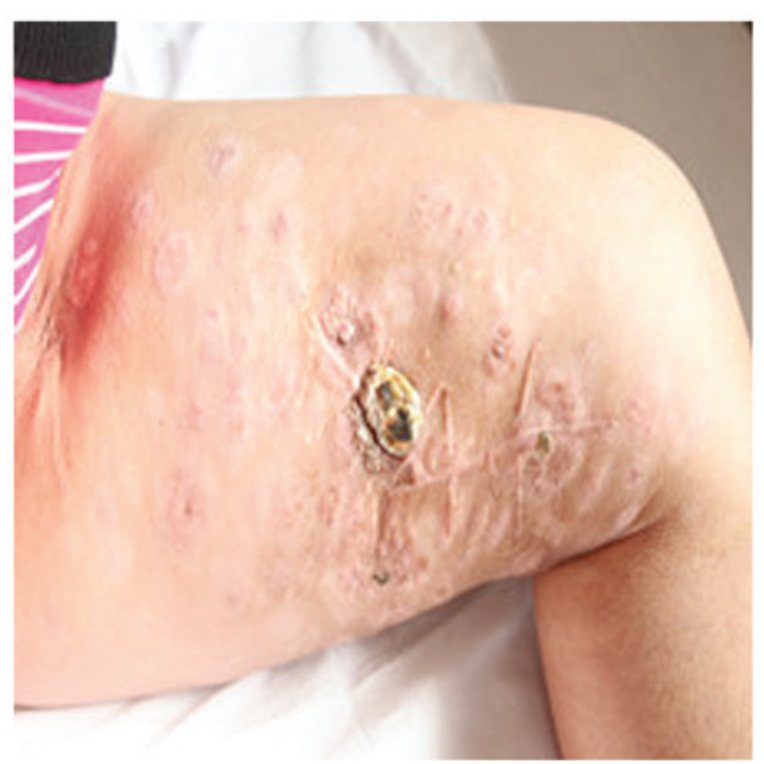

Figure 2. Metastatic melanoma nodes in the patient's left leg following cytokine-induced killer cell therapy.

recombinant human interleukin-1 $\alpha$ (IL-1 $\alpha ; 1,000 \mathrm{U} / \mathrm{ml})$ and interferon- $\gamma(\mathrm{IFN}-\gamma ; 1,000 \mathrm{U} / \mathrm{ml})$, at $37^{\circ} \mathrm{C}$ with $5 \% \mathrm{CO}_{2}$ for $24 \mathrm{~h}$. Next, recombinant human IL-2 (1,000 U/ml) was added to the medium. The medium was replaced with fresh IL- 2 and IFN- $\gamma$-containing medium every 5 days. At day 10 , the CIK cells were harvested and their phenotype was analyzed. All products were free of bacterial, mycoplasma and fungal contamination. The endotoxin activity was $\leq 5$ EU. Phenotypic analysis of the autologous CIK cells in the patient prior to culture and following 10 days of culture demonstrated that the expression of certain antigens in the CIK cells increased during this time as follows: $\mathrm{CD}^{+}$, from $44.39 \pm 6.21$ to $91.36 \pm 8.72 \%$; $\mathrm{CD}^{+} / \mathrm{CD}^{+}$, from $30.08 \pm 4.78$ to $45.63 \pm 7.79 \%$; $\mathrm{CD}^{+} / \mathrm{CD}^{+}$, from $17.96 \pm 6.35$ to
$36.80 \pm 4.45 \%$; $\mathrm{CD}^{+} / \mathrm{CD}^{2} 6^{+}$, from $3.68 \pm 1.47$ to $11.98 \pm 3.91 \%$; and $\mathrm{CD} 25^{+}$, from $17.23 \pm 4.45$ to $32.67 \pm 5.79 \%$, respectively, with $\mathrm{P}<0.05$ for all differences ( $t$-test; SPSS software 11.0; SPSS, Inc., Chicago, IL, USA). The results indicated that the percentages of $\mathrm{CD}^{+}, \mathrm{CD}^{+} / \mathrm{CD}^{+}, \mathrm{CD}^{+} / \mathrm{CD}^{+}$and $\mathrm{CD} 25^{+}$ cells were significantly increased following stimulation and expansion in culture, which is crucial to tumor immunity. The total number of CIK cells transplanted in 1 cycle of CIK therapy was $\sim 5 \times 10^{9}$ cells. Between 10 November 2010 and 27 June 2011, the patient received 8 cycles of CIK cell immunotherapy and $2 \times 10^{6}$ units of IL-2 at days $1-5$ per CIK cell infusion. No adverse reactions were observed during the period of CIK cell therapy. Following 8 cycles of CIK cell immunotherapy, the size and number of metastatic melanoma nodes in the patient's left leg were notably reduced (Fig. 2). The patient underwent re-examination every 3 months. At 1 year after the patient's first CIK cell treatment, re-examination indicated a stable disease state. The patient then received 4 additional cycles of CIK therapy. However, 2 years later, an abdominal contrast-enhanced CT scan indicated that multiple nodes were present in the patient's liver and the treatment was discontinued. The patient succumbed to the disease on March 10, 2013. The overall survival time was 28 months.

Written informed consent was obtained from the patient's family for the publication of this study.

\section{Discussion}

Patients with metastatic melanoma have a median survival of 6-8 months and a 5-year survival of $6 \%(3,4)$. FDA-approved treatments for metastatic melanoma including IL-2, chemotherapy, ipilimumab, vemurafenib, nivolumab and so on, and the median survival time given these treatments is from 6-24 months $(15,22,23)$. Although the survival time of metastatic melanoma patients has improved, novel regimens remain critical to increase it further. In 1991, Schmidt-Wolf et al (11) first reported that CIK cells possessed potential antitumor cell activity in the immunodeficient SCID mouse/human lymphoma model. Following this finding, additional studies indicated that CIK cells may be a better choice for patients with solid tumors and demonstrated that CIKs possess strong antitumor activity in vitro (24-26). A number of previous studies have also demonstrated that CIKs may reverse drug resistance in solid tumor cells (24-26). Therefore CIK cell therapy has been proposed as an alternative therapeutic strategy to adopt for patients with solid tumors. Previous studies have demonstrated that CIK cells are a novel and heterogeneous population of immune effector cells with a high proliferation rate and potent cytotoxic activity against a variety of solid tumors, including renal cell carcinoma, lung cancer and prostate cancer, alone or together with chemotherapy compared with conventional therapies (Table I) $(12,14,20)$.

Since CIK cells possess strong antitumor activity and high amplification efficiency, increasing numbers of studies have administered CIK cell therapy alone or in combination with chemotherapy. Previous studies have demonstrated that CIK cells are a heterogeneous cell population, which express CD3 and CD56 in addition to the natural killer cell NKG2D 
activating receptor. CIK cells possess MHC-unrestricted cytotoxicity towards solid tumors, but not toward normal targets, and may regulate and enhance the cellular immune functions in patients with solid tumors by the secretion of cytokines, such as interferon- $\gamma$, and a number of chemokines, including RANTES, MIP- $1 \alpha$ and MIP-1 $\beta$ (27-30). However, there is currently a lack of studies in which CIK cells were used to treat metastatic malignant melanoma in clinical practice (31). The current case study presents a novel choice of treatment, however, additional cases are required to verify its efficacy.

In conclusion, the results of the present study demonstrate that CIK cells may be easily expanded in vitro, and their transplantation may result in a significant treatment effect in patients with metastatic malignant melanoma. Furthermore, CIK cell therapy is a safe technique that exhibits potential efficacy against metastatic malignant melanoma by significantly enhancing immune function, by increasing the absolute effector cell number without notable side-effects. These results may have a favorable impact on conventional treatments if applied in large-scale studies.

\section{References}

1. Jemal A, Siegel R, Xu J and Ward E: Cancer statistics, 2010 CA Cancer J Clin 60: 277-300, 2010.

2. Ghosh P and Chin L: Genetics and genomics of melanoma. Expert Rev Dermatol 4: 131, 2009.

3. Balch CM, Soong SJ, Gershenwald JE, et al: Prognostic factors analysis of 17,600 melanoma patients: Validation of the American Joint Committee on Cancer melanoma staging system. J Clin Oncol 19: 3622-3634, 2001

4. Barth A, Wanek LA and Morton DL: Prognostic factors in 1,521 melanoma patients with distant metastases. J Am Coll Surg 181: 193-201, 1995

5. Hontscha C, Borck Y, Zhou H, Messmer D and Schmidt-Wolf IG: Clinical trials on CIK cells: First report of the international registry on CIK cells (IRCC). J Cancer Res Clin Oncol 137: 305-310, 2011.

6. Schwaab T, Schwarzer A, Wolf B, et al: Clinical and immunologic effects of intranodal autologous tumor lysate-dendritic cell vaccine with Aldesleukin (Interleukin 2) and IFN-\{alpha\}2a therapy in metastatic renal cell carcinoma patients. Clin Cancer Res 15: 4986-4992, 2009.

7. Rosenberg SA, Spiess P and Lafreniere R: A new approach to the adoptive immunotherapy of cancer with tumor-infiltrating lymphocytes. Science 233: 1318-1321, 1986.

8. Rosenberg S: Lymphokine-activated killer cells: A new approach to immunotherapy of cancer. J Natl Cancer Inst 75: 595-603, 1985

9. Yun YS, Hargrove ME and Ting CC: In vivo antitumor activity of anti-CD3-induced activated killer cells. Cancer Res 49: 4770-4774, 1989.

10. Shablak A, Hawkins RE, Rothwell DG and Elkord E: $\mathrm{T}$ cell-based immunotherapy of metastatic renal cell carcinoma: Modest success and future perspective. Clin Cancer Res 15: 6503-6510, 2009.

11. Schmidt-Wolf IG, Negrin RS, Kiem HP, Blume KG and Weissman IL: Use of a SCID mouse/human lymphoma model to evaluate cytokine-induced killer cells with potent antitumor cell activity. J Exp Med 174: 139-149, 1991.

12. Li R, Wang C, Liu L, et al: Autologous cytokine-induced killer cell immunotherapy in lung cancer: a phase II clinical study. Cancer Immunol Immunother 61: 2125-2133, 2012.
13. Shi L, Zhou Q, Wu J, et al: Efficacy of adjuvant immunotherapy with cytokine-induced killer cells in patients with locally advanced gastric cancer. Cancer Immunol Immunother 61: 2251-2259, 2012

14. Liu L, Zhang W, Qi X, et al: Randomized study of autologous cytokine-induced killer cell immunotherapy in metastatic renal carcinoma. Clin Cancer Res 18: 1751-1759, 2012.

15. Hersey P: Immunotherapy of melanoma. Asia Pac J Clin Oncol 6 Suppl 1: S2-S8, 2010.

16. Schmidt-Wolf IG, Finke S, Trojaneck B, et al: Phase I clinical study applying autologous immunological effector cells transfected with the interleukin-2 gene in patients with metastatic renal cancer, colorectal cancer and lymphoma. Br J Cancer 81: 1009-1016, 1999

17. Jiang J, Xu N, Wu C, et al: Treatment of advanced gastric cancer by chemotherapy combined with autologous cytokine-induced killer cells. Anticancer Res 26 (3B): 2237-2242, 2006.

18. Wu C, Jiang J, Shi L and Xu N: Prospective study of chemotherapy in combination with cytokine-induced killer cells in patients suffering from advanced non-small cell lung cancer. Anticancer Res 28 (6B): 3997-4002, 2008.

19. Hui D, Qiang L, Jian W, Ti Z and Da-Lu K: A randomized, controlled trial of postoperative adjuvant cytokine-induced killer cells immunotherapy after radical resection of hepatocellular carcinoma. Dig Liver Dis 41: 36-41, 2009.

20. Li W, Xu LP, DI Zhao L, et al: Cytokine-induced killer cell therapy for advanced pancreatic adenocarcinoma: A case report and review of the literature. Oncol Lett 5: 1427-1429, 2013.

21. Huang ZM, Li W, Li S, et al: Cytokine-induced killer cells in combination with transcatheter arterial chemoembolization and radiofrequency ablation for hepatocellular carcinoma patients. J Immunother 36: 287-293, 2013.

22. Alexandrescu DT, Ichim TE, Riordan NH, et al: Immunotherapy for melanoma: Current status and perspectives. J Immunother 33: 570-590, 2010.

23. Robert C, Long GV, Brady B, et al: Nivolumab in previously untreated melanoma without BRAF mutation. N Engl J Med 372: 320-330, 2015.

24. Zhao Q, Zhang H, Li Y, Liu J, Hu X and Fan L: Anti-tumor effects of CIK combined with oxaliplatin in human oxaliplatin-resistant gastric cancer cells in vivo and in vitro. J Exp Clin Cancer Res 29: 118, 2010.

25. Wang FS, Liu MX, Zhang B, et al: Antitumor activities of human autologous cytokine-induced killer (CIK) cells against hepatocellular carcinoma cells in vitro and in vivo. World $\mathrm{J}$ Gastroenterol 8: 464-468, 2002.

26. Zhang YS, Yuan FJ, Jia GF, et al: CIK cells from patients with HCC possess strong cytotoxicity to multidrug-resistant cell line Bel-7402/R. World J Gastroenterol 11: 3339-3345, 2005.

27. Karimi M, Cao TM, Baker JA, Verneris MR, Soares L and Negrin RS: Silencing human NKG2D, DAP10 and DAP12 reduces cytotoxicity of activated CD8+ T cells and NK cells. J Immunol 175: 7819-7828, 2005.

28. Verneris MR, Karami M, Baker J, Jayaswal A and Negrin RS: Role of NKG2D signaling in the cytotoxicity of activated and expanded CD8+ T cells. Blood 103: 3065-3072, 2004.

29. Schmidt-Wolf IG, Lefterova P, Mehta BA, et al: Phenotypic characterization and identification of effector cells involved in tumor cell recognition of cytokine-induced killer cells. Exp Hematol 21: 1673-1679, 1993.

30. Joshi PS, Liu JQ, Wang Y, et al: Cytokine-induced killer $\mathrm{T}$ cells kill immature dendritic cells by TCR-independent and perforin-dependent mechanisms. J Leukoc Biol 80: 1345-1353, 2006

31. Gammaitoni L, Giraudo L and Leuci V, et al: Effective activity of cytokine-induced killer cells against autologous metastatic melanoma including cells with stemness features. Clin Cancer Res 19: 4347-4358, 2013. 